\title{
Structural Response of Unreinforced Masonry Walls
}

\author{
Nelson Darío Agüera, Miguel Eduardo Tornello and Carlos Daniel Frau \\ Regional Centre Technology Development for Construction, Seismology and Earthquake Engineering, National Technological \\ University, Mendoza 5525, Argentina
}

\begin{abstract}
Historical buildings located in seismic regions have URM (unreinforced masonry) walls of considerable width as their main structure. In order to study the structural response of such type of masonry, it is necessary to know its mechanical and elastic characteristics. For such purpose, it is generally necessary to perform destructive and non-destructive tests. Other procedures, such as the study of masonry through numerical models, would make it possible to predict, with close approximation, the response of masonry to different actions. The purpose of this paper is to evaluate the behavior of URM walls subjected to axial and horizontal load by using a finite element model with the Abaqus code. Constitutive laws of materials, bricks and mortar are defined, using two constitutive models of plasticity and damage included in the materials library. The constitutive models used employ information of experimental tests performed on bricks and mortar. The results of an analysis for an URM wall subjected to axial and horizontal load are presented. Responses of walls were obtained in terms of load versus displacement for different constitutive models and for different qualities of bricks and mortar. The two constitutive models used show similar results, particularly in the response waveforms. However, the ultimate capacity values show mean variations of around 30\%. The two constitutive models display high dependence upon the mechanical characteristics of bricks and mortar.
\end{abstract}

Key words: Masonry, structural behavior, piles.

\section{Introduction}

Throughout history, the use of masonry as construction material has been a widely used typology even after the appearance of new materials such as reinforced concrete and steel. Therefore, a significant percentage of buildings with heritage value are built exclusively with masonry walls. Those elements, which also perform a structural function, have an important role in the seismic response of the building when subjected to demanding conditions, permanent loads, overload use and seismic actions if they are located in seismic risk regions. Due to this last factor, the study of structural behavior of masonry buildings subjected to seismic action is of special importance.

Additionally, the structural analysis of historical masonry buildings for seismic evaluation is still a challenge owing to a series of factors amongst which the following are to be remarked:

Corresponding author: Nelson Darío Agüera, Ph.D. candidate, research fields: earthquake structures and masonry structures.
(1) the low tension strength with quasi-fragile failure of masonry, which implies a non-linear behavior from small load intensities;

(2) the great heterogeneity normally present in these buildings, which makes it difficult to assign global mechanical properties to the material model;

(3) the heterogeneous character of the material;

(4) the non-associated nature of shear failure, owing to the difference between the dilation angle and the internal friction angle of masonry;

(5) the planes of weakness commonly represented by joints, which may or may not have well-defined orientations depending on their geometrical arrangement.

Most of the research performed on URM (unreinforced masonry) walls in the area of seismic behavior is based on experimental or numerical analyses [1-6]. In the field of experimental seismic research, different approaches to tests have been used for URM structures, that is, monotonic tests or quasi-static cyclic tests, dynamic tests on vibration 
table, and pseudo-dynamic tests. Dynamic tests can simulate seismic action with more accuracy, although the quasi-static cyclic tests make it possible to obtain more accurate measurements of forces and displacements, and the recording of damage evolution becomes simpler [7]. Masonry walls are normally tested in laboratory under constant vertical load, varying the horizontal load [8]. The typical configuration for quasi-static tests was suggested in such a way that the masonry panel is fixed in its bottom part and left loose in its upper part [9]. This testing device, together with cyclic load, provides vital information (failure mode and damage evolution, form of hysteresis cycle, and dissipation of energy) for the evaluation of the seismic response of masonry walls [10].

A comprehensive analysis of cyclic behavior in the masonry wall-plane under shear was achieved through quasi-static tests on historical buildings' masonry walls [11]. Another study on cyclic behavior in the masonry plane was carried out in 2003 [10], where brick masonry panels with different types of mortar joints were analyzed.

Masonry is a material that exhibits directionality in its properties due to the fact that mortar joints act as planes of weakness in the material. In general, approximation towards a numeric modeling can be handled with micro-models, which in a detailed and separate manner make a discrete division of bricks and joints. In addition, a macro-model can be applied in which masonry is treated as a heterogeneous material [12].

Significant advances have been achieved in the field of the strategies of micro- and macro-modeling to identify the response of masonry walls to different actions [13]. Analyses of masonry by using the micro-modeling tool is convenient for small structural elements, with a special interest in the conditions of stress and strain in the panel. In order to represent such behavior, it is necessary to have a good knowledge of each constituent element of masonry and the interaction generated among such elements [14]. The behavior of URM when subjected to seismic actions may be understood by means of a tri-dimensional analysis of masonry panels by using the computational tools of modeling and by describing the elastic and inelastic characteristics of the materials used in the constitutive model [15].

Some scientific advances are made by the above-mentioned authors and in relation to:

(1) the fact that for the study of URM walls of reduced dimensions, it is convenient to use micro-modeling;

(2) the fact that the structural response depends on the elastic and inelastic properties of materials;

(3) the fact that the different plasticity models used to represent masonry behavior numerically lead to varied structural responses.

This paper proposes a comprehensive analysis of URM walls in which all the variables mentioned above are contemplated.

The present paper aims at determining the structural response of URM walls through numerical simulation of masonry walls, using micro-modeling to represent the numerical model, and using two different plasticity criteria. To that purpose, it is counted on information about the mechanical behavior of the materials that make up the URM walls, bricks and mortar. As a work tool, commercial Abaqus code [16] is used, which makes it possible to generate a model of finite elements to formulate conclusions about the results of the numerical simulation of the walls.

\section{Plasticity Models}

The irreversible deformations resulting from displacement mechanisms or from dislocations at atomic scale, and which therefore lead to permanent dimensional changes, are known as plastic strain. Such deformations occur at stress values above a threshold value known as elastic boundary or yield stress. Within the field of plasticity theory, the fundamental issue consists in the mathematical formulation of the 
stress-strain relationships suitable for an adequate description of plastic strain, and also in the adoption of an appropriate yield criterion to predict the onset of plastic behavior [17]. The mathematical formulation of stress-strain is done through the use of plasticity models.

\subsection{DP (Drucker-Prager) Model}

Drucker-Prager defines a family of plasticity models in which the behavior of materials depends upon the equivalent compressive stress. It is used to model frictional materials in which yield strength to compression is greater than that for tension. The model allows the material to have isotropic hardening and softening. The yield criteria is based on the shape of the yield surface in the meridional plane. The yield surface may have a linear, hyperbolic or exponential mode.

The evolution of the yield surface with plastic deformation is described in terms of equivalent stress, which can be one of the following values: yield stress at uniaxial compression, yield stress at uniaxial tension, or yield stress at shear (cohesion).

The surface of yield stress makes use of two invariants, defined as equivalent pressure stress:

$$
p=-\frac{1}{3} \operatorname{trace}(\sigma)
$$

where, trace is the trace of the matrix. The Mises equivalent stress is defined through the following expression:

$$
q=\sqrt{\frac{3}{2}(S: S)}
$$

where, $S$ is the stress deviator given by the following expression:

$$
S=\sigma+p I
$$

where, $\sigma$ is the stress matrix and $p$ is the equivalent pressure stress.

The linear model uses the third invariant of deviatoric stress:

$$
r=\left(\frac{9}{2} S \cdot S: S\right)^{\frac{1}{3}}
$$

in which $r$ is the determinant of deviatoric stress $S$.

\subsection{CDP (Concrete Damaged Plasticity) Model}

The model has a good capacity to model concrete and other quasi-brittle materials in all types of structures. It uses concepts of isotropic damage elasticity in combination with isotropic tension and compressive plasticity to represent the inelastic behavior of concrete. The model takes into account the degradation of the elastic stiffness induced by plastic stress both at traction and at compression, and it adequately explains the effects of stiffness recovery under cyclic load.

It is necessary to define the behavior in the material stress-strain plane in uniaxial compression out of the elastic range. The data on compressive stress is shown as a function of inelastic strain, and the stress-strain curve can be defined beyond the ultimate stress, into the strain-softening regime. The data on hardening can be expressed in terms of inelastic strain instead of plastic strain. The compressive inelastic strain is defined as the total strain minus the elastic strain corresponding to the undamaged material [16].

The Abaqus program automatically converts the inelastic strain values to plastic strain values using the following relationship:

$$
\varepsilon_{c}^{p l}=\varepsilon^{i n}-\frac{d_{c}}{\left(1-d_{c}\right)} \frac{\sigma_{c}}{E_{0}}
$$

where:

$\varepsilon_{c}^{p l}=$ plastic strain;

$\varepsilon^{\text {in }}=$ inelastic strain;

$d_{c}=$ variable of stiffness degradation;

$E_{0}=$ initial elasticity modulus;

$\sigma_{c}=$ compressive stress.

Effective stress is defined as:

$$
\bar{\sigma}=D_{0}^{e l}:\left(\varepsilon-\varepsilon^{p l}\right)
$$

where, $D_{0}^{e l}=$ the initial (undamaged) elasticity matrix.

The plastic flow potential function and the yield surface make use of two stress invariants of the effective stress tensor, namely the hydrostatic pressure stress (Eq. (7)) and the Mises equivalent effective stress (Eq. (8)): 


$$
\begin{aligned}
\bar{p} & =-\frac{1}{3} \operatorname{trace}(\bar{\sigma}) \\
\bar{q} & =\sqrt{\frac{3}{2}(\bar{S}: \bar{S})}
\end{aligned}
$$

where, $\bar{S}$ effective stress deviator is defined as:

$$
\bar{S}=\bar{\sigma}+\bar{p} I
$$

\section{Masonry Piles}

The URM walls analyzed in this paper have a width of $450 \mathrm{~mm}$. The rest of the geometry is shown in Fig. 1.

Solid clay brick (290 mm long, $140 \mathrm{~mm}$ wide and $70 \mathrm{~mm}$ high) is used. Bricks are laid with combined cement and lime mortar with an average thickness of $20 \mathrm{~mm}$.

\section{Finite Element Model}

In order to model the masonry wall, solid deformable elements in three dimensions of the C3D8R type were used. The latter is a standard element of Abaqus with eight contact nodes, reduced integration and hourglass control. Interaction elements were used to simulate the contact joints between bricks and mortar. The contacts between surfaces were defined with the "surface-surface" Abaqus option, specifying master surfaces and slave surfaces in which the master surface cannot be penetrated by the slave surface. The interaction between surfaces was defined for longitudinal and transversal behavior. For the former, a behavior of rigid or hard contact was specified; for the latter, a frictional behavior was specified with friction penalty according to the friction coefficient defined. Fig. 2 shows the model of finite elements used. The URM walls analyzed in this project are $450 \mathrm{~mm}$ wide, $600 \mathrm{~mm}$ long and $580 \mathrm{~mm}$ high.

\subsection{Material Characteristics for Models Used}

Two groups of materials with distinctive features for bricks and mortar were defined. The parameters of the first group, designated as "P\#1", were obtained from the paper Non-linear Analysis of Walls of Considerable Width through the Application of Surface Interaction in Abaqus [18]. The characteristics of the second group, designated as "P\#2", were determined through experimental tests of bricks and mortar.

\subsection{DP (Drucker-Prager) Model in Abaqus}

The mechanical and elastic characteristics in the DP models for the two groups of bricks studied are shown in Tables 1-3.

Tables 4-6 display the mechanical and elastic characteristics considered in the DP models for the two groups of mortar analyzed.

\subsection{CDP (Concrete Damaged Plasticity Model) in Abaqus}

The two characteristics of brick used in the CDP model are summarized in Tables 7-9.

The characteristics of mortar used in the CDP model are shown in Tables 10-12.

\subsection{Hypothesis of Boundary Conditions}

Finite elements have restriction at the bottom part of the wall, in coincidence with the simple concrete slab (Fig. 1), in the three possible displacement directions. Two types of actions were defined. The first one consists

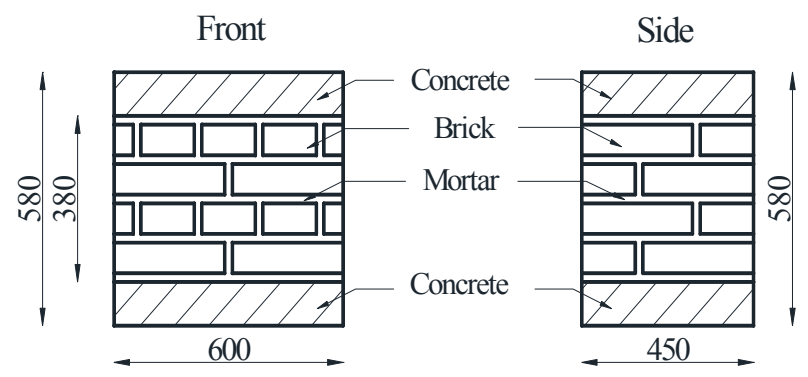

Fig. 1 Schematic drawing of masonry wall (units in $\mathbf{m m}$ ).

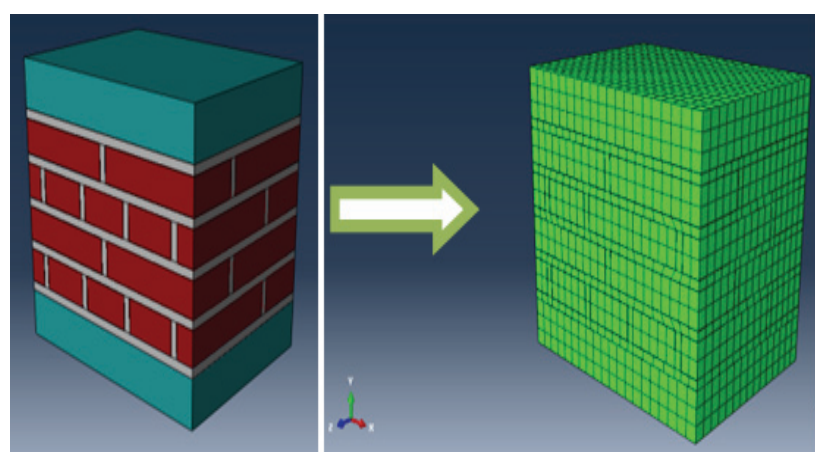

Fig. 2 Model of finite elements used on the Abaqus platform. 
Table 1 Elastic characteristic of brick (kN-mm).

\begin{tabular}{lllllll}
\hline P\#1 & & & & & \\
\cline { 1 - 1 } Mass density & $E$ & Mass density & $E$ & Poisson coefficient \\
\hline $0.00143 \times \mathrm{E}-05$ & 0.2170 & 0.155 & $0.00151 \times \mathrm{E}-05$ & 0.6540 & 0.160 \\
\hline
\end{tabular}

Table 2 DP characteristics of brick. Criterion of hyperbolic shear (kN-mm).

\begin{tabular}{lllllll}
\hline $\mathrm{P} \# 1$ & & & $\mathrm{P} \# 2$ & & \\
\cline { 1 - 2 } \cline { 5 - 6 } Angle of friction & Init tension & Dilation angle & & Angle of friction & Init tension & Dilation angle \\
\hline 15.5 & $26 \times \mathrm{E}-04$ & 7 & 15.5 & $11.2 \times \mathrm{E}-04$ & 7 \\
\hline
\end{tabular}

Table 3 Non-linear characteristics of brick. Hardening by compression $(\mathrm{kN}-\mathrm{mm})$.

\begin{tabular}{llll}
\hline P\#1 & & P\#2 & \\
\cline { 1 - 2 } Yield stress & Absolute plastic strain & & Yield stress \\
\hline $51.67 \times \mathrm{E}-04$ & 0 & $106.3 \times \mathrm{E}-04$ & 0 \\
$56.37 \times \mathrm{E}-04$ & 0.001169 & $139.9 \times \mathrm{E}-04$ & 0.0079 \\
$61.07 \times \mathrm{E}-04$ & 0.003095 & $142.8 \times \mathrm{E}-04$ & 0.0094 \\
$65.77 \times \mathrm{E}-04$ & 0.005325 & $135.9 \times \mathrm{E}-04$ & 0.0174 \\
$70.46 \times \mathrm{E}-04$ & 0.009827 & $116.9 \times \mathrm{E}-04$ & 0.0294 \\
$71.4 \times \mathrm{E}-04$ & 0.017576 & $92.0 \times \mathrm{E}-04$ & 0.0384 \\
$7.14 \times \mathrm{E}-04$ & 0.2 & - & - \\
\hline
\end{tabular}

Table 4 Elastic characteristics of mortar $(\mathrm{kN}-\mathrm{mm})$.

\begin{tabular}{|c|c|c|c|c|c|}
\hline P\#1 & & & $\mathrm{P} \# 2$ & & \\
\hline Mass density & $E$ & Poisson coefficient & Mass density & $E$ & Poisson coefficient \\
\hline $0.0024 \times E-05$ & 0.7760 & 0.21 & $0.00186 \times \mathrm{E}-05$ & 0.1553 & 0.22 \\
\hline
\end{tabular}

Table 5 DP characteristics of mortar. Criterion of hyperbolic shear ( $\mathrm{kN}-\mathrm{mm})$.

\begin{tabular}{lllllll}
\hline $\mathrm{P} \# 1$ & & & $\mathrm{P} \# 2$ & & \\
\cline { 1 - 2 } Angle of friction & Init tension & Dilation angle & & Angle of friction & Init tension & Dilation angle \\
\hline 15.5 & $6 \times \mathrm{E}-04$ & 7 & 15.5 & $10.5 \times \mathrm{E}-04$ & 7 \\
\hline
\end{tabular}

Table 6 Non-linear characteristics of mortar. Hardening by compression $(\mathrm{kN}-\mathrm{mm})$.

\begin{tabular}{llll}
\hline P\#1 & & P\#2 & \\
\cline { 1 - 2 } Yield stress & Absolute plastic strain & & Yield stress \\
\hline $50.02 \times$ E-04 & 0 & $21.73 \times \mathrm{E}-04$ & 0 \\
$60.02 \times \mathrm{E}-04$ & 0.001776 & $23.87 \times \mathrm{E}-04$ & 0.0029 \\
$66.02 \times \mathrm{E}-04$ & 0.003619 & $24.33 \times \mathrm{E}-04$ & 0.0049 \\
$6.602 \times \mathrm{E}-04$ & 0.2 & $22.32 \times \mathrm{E}-04$ & 0.00825 \\
- & - & $17.40 \times \mathrm{E}-04$ & 0.01275 \\
- & - & $5.30 \times \mathrm{E}-04$ & 0.02605 \\
\hline
\end{tabular}

Table 7 Elastic characteristics of brick $(\mathrm{kN}-\mathbf{m m})$.

\begin{tabular}{|c|c|c|c|c|c|}
\hline$\overline{\mathrm{P} \# 1}$ & & & $\mathrm{P} \# 2$ & & \\
\hline Mass density & $E$ & Poisson coefficient & Mass density & $E$ & Poisson coefficient \\
\hline $0.00143 \times \mathrm{E}-05$ & 0.2170 & 0.155 & $0.00151 \times \mathrm{E}-05$ & 0.6540 & 0.160 \\
\hline
\end{tabular}


Table 8 CDP characteristics of brick $(\mathrm{kN}-\mathrm{mm})$.

\begin{tabular}{lllll}
\hline $\mathrm{P} \# 1$ & & & \\
\hline Dilation angle & Eccen-tricity & $f b_{0} / f c_{0}$ & $k$ & Viscosity parameter \\
\hline 7 & 0.1 & 1.16 & 0.66 & 0.0005 \\
\hline $\mathrm{P} \# 2$ & & & Viscosity parameter \\
\hline Dilation angle & Eccen-tricity & $f b_{0} / f c_{0}$ & $k$ & 0.0005 \\
\hline 7 & 0.1 & 1.16 & 0.66 & \\
\hline
\end{tabular}

Table 9 Non-linear characteristics of brick $(\mathrm{kN}-\mathrm{mm})$.

\begin{tabular}{|c|c|c|c|}
\hline \multicolumn{4}{|l|}{$\mathrm{P} \# 1$} \\
\hline \multicolumn{2}{|c|}{ Behavior at compression } & \multicolumn{2}{|c|}{ Behavior at tension } \\
\hline Yield stress $(1 \times \mathrm{E}-04)$ & Inelastic strain & Yield stress $(1 \times \mathrm{E}-04)$ & Cracking strain \\
\hline 51.67 & 0 & 26.1 & 0 \\
\hline 56.37 & 0.001169 & - & - \\
\hline 61.07 & 0.003095 & - & - \\
\hline 65.77 & 0.005325 & - & - \\
\hline 70.46 & 0.009827 & - & - \\
\hline 71.4 & 0.017576 & - & - \\
\hline 7.14 & 0.2 & - & - \\
\hline \multicolumn{4}{|l|}{$\mathrm{P} \# 2$} \\
\hline \multicolumn{2}{|c|}{ Behavior at compression } & \multicolumn{2}{|c|}{ Behavior at tension } \\
\hline Yield stress $(1 \times \mathrm{E}-04)$ & Inelastic Strain & Yield stress $(1 \times \mathrm{E}-04)$ & Cracking strain \\
\hline 106.3 & 0 & 11.2 & 0 \\
\hline 139.9 & 0.0079 & - & - \\
\hline 142.8 & 0.0094 & - & - \\
\hline 135.9 & 0.0174 & - & - \\
\hline 116.9 & 0.0294 & - & - \\
\hline 92.0 & 0.0384 & - & - \\
\hline
\end{tabular}

Table 10 Elastic characteristics of mortar (kN-mm).

\begin{tabular}{|c|c|c|c|c|c|}
\hline $\mathrm{P \# 1}$ & & & $\mathrm{P \# 2}$ & & \\
\hline Mass density & $E$ & Poisson coefficient & Mass density & $E$ & Poisson coefficient \\
\hline $0.0024 \times \mathrm{E}-05$ & 0.7760 & 0.21 & $0.00186 \times \mathrm{E}-05$ & 0.1553 & 0.22 \\
\hline
\end{tabular}

Table 11 CDP Characteristics of mortar (kN-mm).

\begin{tabular}{lllll}
\hline $\mathrm{P} \# 1$ & & & \\
\hline Dilation angle & Eccen-tricity & $f b_{0} / f c_{0}$ & $k$ & Viscosity parameter \\
\hline 7 & 0.1 & 1.16 & 0.66 & 0.0005 \\
\hline $\mathrm{P} \# 2$ & & & Viscosity parameter \\
\hline Dilation angle & Eccen-tricity & $f b_{0} / f c_{0}$ & $k$ & 0.0005 \\
\hline 7 & 0.1 & 1.16 & 0.66 & \\
\hline
\end{tabular}

in a constant vertical stress, in coincidence with the vertical axis of the wall with values of $1 \mathrm{MPa}, 0.5 \mathrm{MPa}$ and 0.1 MPa. The second action is a horizontal displacement of $20 \mathrm{~mm}$ for a constant vertical stress value (Fig. 3).

\section{Results and Discussion}

Wall responses were evaluated in terms of horizontal displacement curves versus horizontal forces for each constitutive model, for each vertical stress value and for a constant displacement of $20 \mathrm{~mm}$. Results were obtained for the two types of bricks and mortar mentioned.

Figs. 4 and 5 show the curves for the two constitutive models (DP and CDP) for the vertical stress values defined and for the materials designated as 
Table 12 Non-linear characteristics of mortar $(\mathrm{kN}-\mathrm{mm})$.

\begin{tabular}{llll}
\hline P\#1 & & & \\
\cline { 1 - 2 } Behavior at compression & & Yehavior at tension & \\
\hline Yield stress $(1 \times \mathrm{E}-04)$ & Inelastic strain & 6.602 & Cracking strain \\
\hline 50.02 & 0 & 0.660 & 0 \\
60.02 & 0.001776 & - & -2 \\
66.02 & 0.003619 & - & - \\
6.602 & 0.2 & & - \\
\hline P\#2 & & Behavior at Tension & \\
\hline Behavior at compression & & Yield stress $(1 \times$ E- -04$)$ & Cracking strain \\
\hline Yield stress $(1 \times$ E-04) & Inelastic strain & 10.5 & 0 \\
\hline 21.73 & 0 & - & - \\
23.87 & 0.0029 & - & - \\
24.33 & 0.0049 & - & - \\
22.32 & 0.00825 & - & - \\
17.4 & 0.01275 & - & - \\
5.3 & 0.02605 & &
\end{tabular}

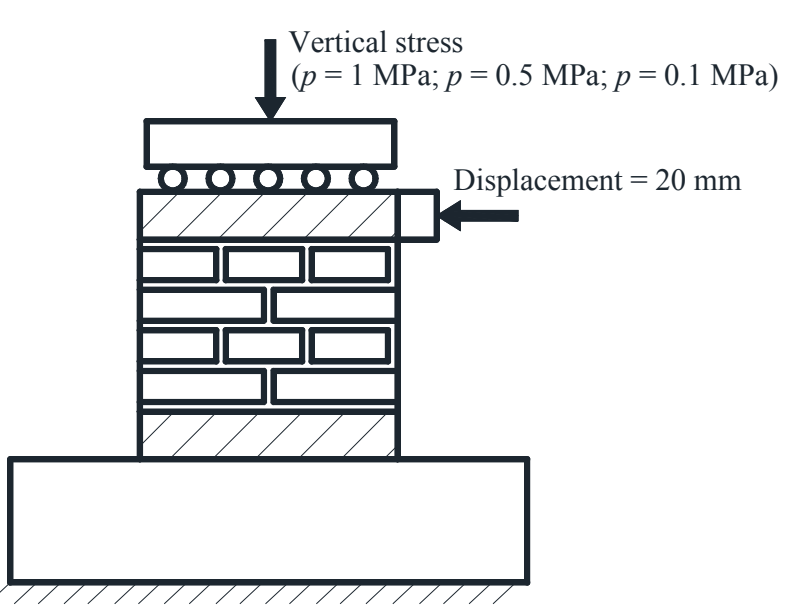

Fig. 3 Boundary conditions and schematic illustration of load on the masonry wall.

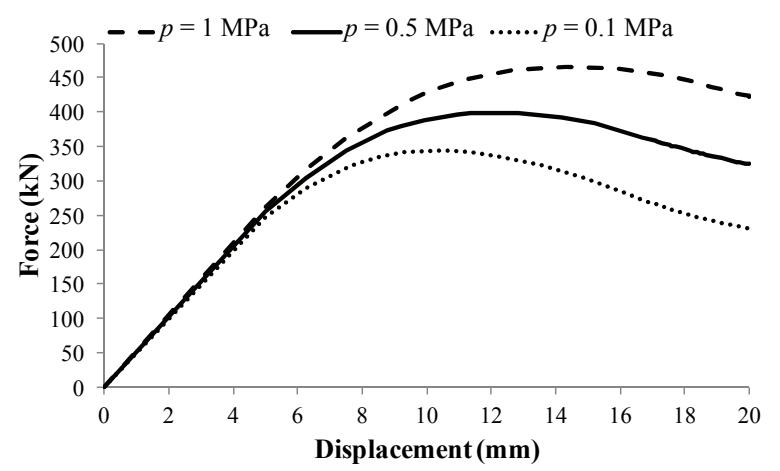

Fig. 4 Force versus displacement curves, DP model with P\#1 materials $(p=1 \mathrm{MPa}, p=0.5 \mathrm{MPa}$ and $p=0.1 \mathrm{MPa})$.

"Properties \#1" (P\#1). The results shown in Fig. 4 indicate that for the DP model the value of ultimate horizontal load does not correspond to the same horizontal displacement, which is influenced by the increase in vertical load. The ultimate horizontal load varies linearly with the increase in vertical load.

Fig. 5 shows the results obtained for the CDP model, which indicate the differences in relation to the DP model. The peak load determined corresponds to the same horizontal displacement for vertical stress values of $0.5 \mathrm{MPa}$ and $0.1 \mathrm{MPa}$. In addition, the increase of vertical stress leads to non-linear variation of the peak horizontal load.

Fig. 6 shows the status of shear stress for the DP model for $\mathrm{P} \# 1$ materials for a vertical stress value of $1 \mathrm{MPa}$. Fig. 7 shows the mapping of plastic strain for the DP model for P\#1 materials with a vertical stress value of $p=1 \mathrm{MPa}$. Fig. 8 shows the distribution of shear stress for the CDP model for P\#1 materials with a vertical stress value of $p=1 \mathrm{MPa}$. Fig. 9 illustrates the mapping of plastic strain for the CDP model for P\#1 materials with a vertical stress value of $p=1 \mathrm{MPa}$.

Shear stress shown in Fig. 6 indicates maximum values concentrated over a centered diagonal band, oriented approximately $45^{\circ}$ with respect to the horizontal. On the other hand, Fig. 8 shows that the maximum shear stress is not concentrated along a central diagonal band; plastification on the wall develops 


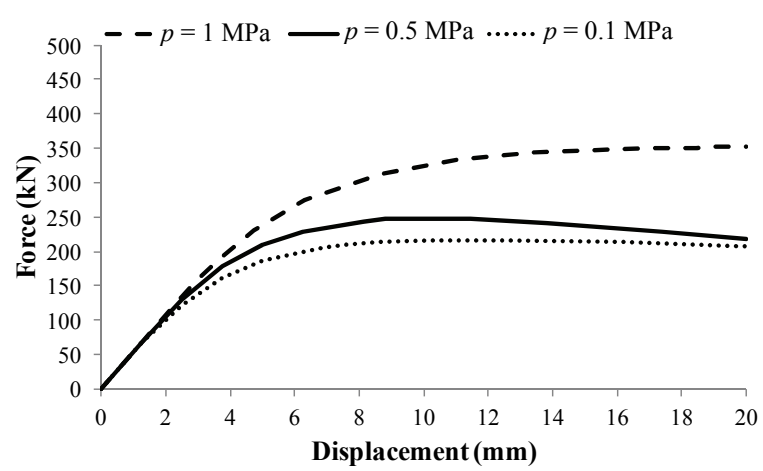

Fig. 5 Force versus displacement curves, CDP model with P\#1 materials ( $p=1 \mathrm{MPa}, p=0.5 \mathrm{MPa}$ and $p=0.1 \mathrm{MPa})$.

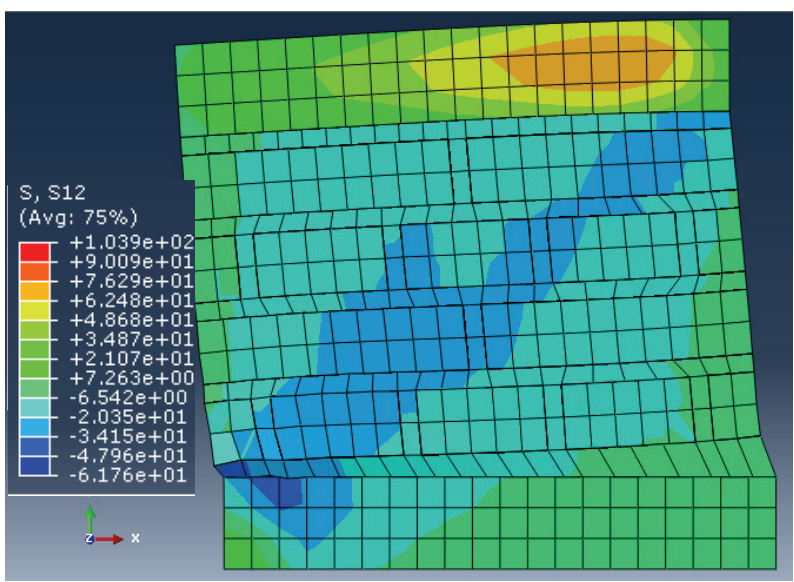

Fig. 6 Status of shear stress, DP model with P\#1 materials, $p=1 \mathrm{MPa}(\mathrm{MPa} \times \mathbf{E}-\mathbf{0 1})$.

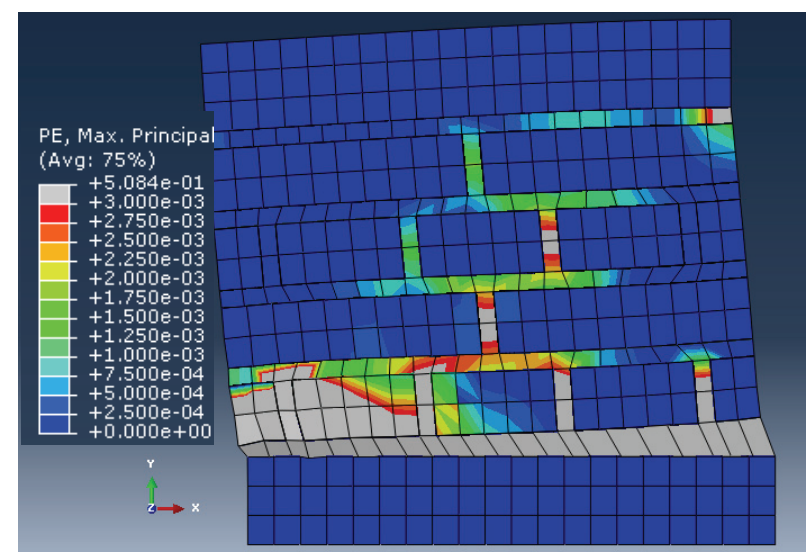

Fig. 7 Mapping of plastic strain, DP model with P\#1 materials, $p=1 \mathrm{MPa}(\mathrm{MPa} \times \mathbf{E}-\mathbf{0 1})$.

over a more extended area and not on a localized zone. Fig. 9 shows that plastic strain is present in different zones, which mainly coincide with mortar joints.

Figs. 10-12 compare the response of the two constitutive models (DP-CDP) for P\#1 materials.

Figs. 10-12 show that the CDP model reaches lower

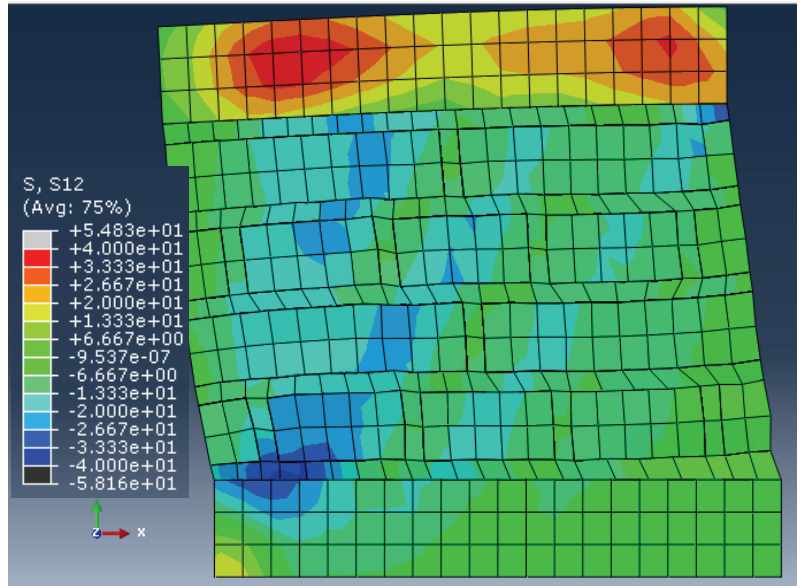

Fig. 8 Status of shear stress, CDP model with P\#1 materials, $p=1 \mathrm{MPa}(\mathrm{MPa} \times \mathrm{E}-\mathbf{0 1})$.

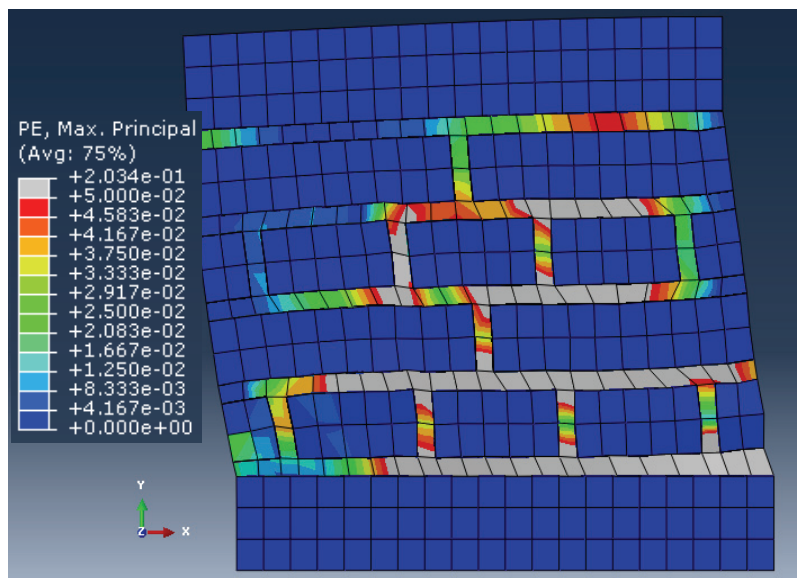

Fig. 9 Mapping of plastic strain, CDP model with P\#1 materials, $p=1 \mathrm{MPa}(\mathrm{MPa} \times \mathbf{E}-\mathbf{0 1})$.

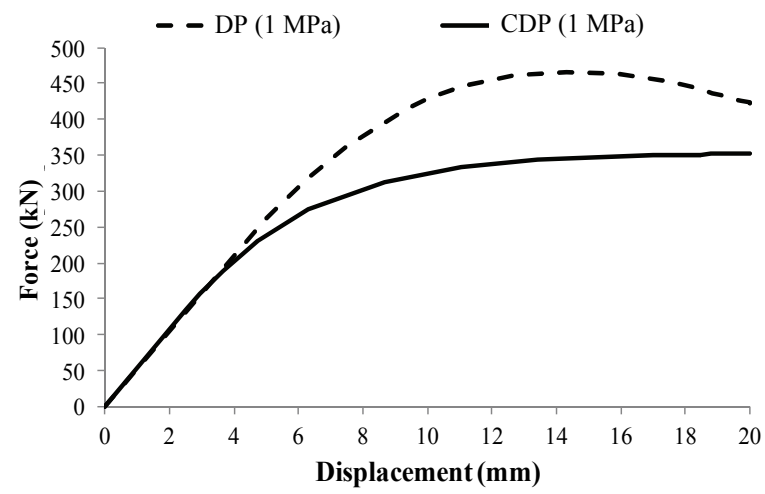

Fig. 10 Force versus displacement curves, comparison between the two models of materials used, $\mathrm{P} \# 1$ materials $(p=1 \mathrm{MPa})$.

levels of peak horizontal load than the DP model. Similarly, the forces and initial yield displacement are lower for the CDP model than that for the DP model. The DP model presents degradation of the horizontal 


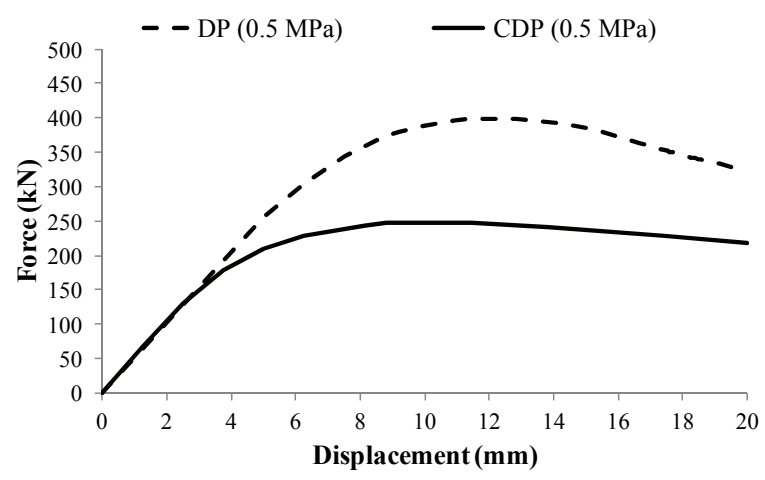

Fig. 11 Force versus displacement, comparison between the two models of materials used, P\#1 materials $(p=0.5 \mathrm{MPa})$.

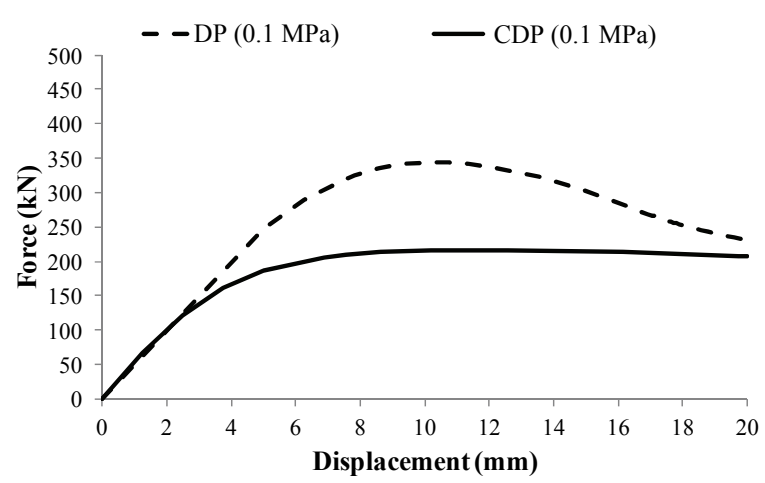

Fig. 12 Force versus displacement curves, comparison between the two models of materials used, P\#1 materials $(p=0.1 \mathrm{MPa})$.

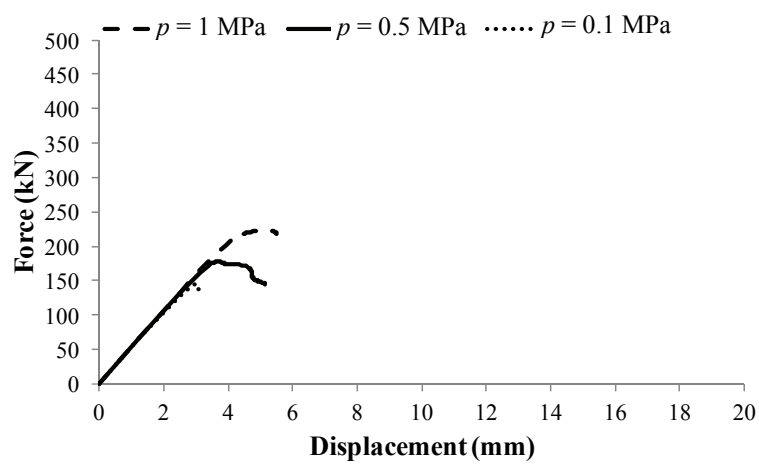

Fig. 13 Force versus displacement curves, DP model with P\#2 materials $(p=1 \mathrm{MPa}, p=0.5 \mathrm{MPa}$ and $p=0.1 \mathrm{MPa})$.

force after reaching its maximum value; However, in the CDP model, this occurs only for the vertical stress level of $0.5 \mathrm{MPa}$. For the rest of the vertical stress applied, the peak horizontal force does not decrease until it reaches the maximum displacement imposed. These differences are attributed to the fact that plastic strain manifests itself in different ways in the two models analyzed. In the CDP model, plastic strain is spread along a larger area than in the DP model.

Figs. 13 and 14 show the horizontal force versus horizontal displacement curves for the two constitutive models (DP and CDP), for the vertical stress values defined, and for materials called "Properties \#2" (P\#2).

Fig. 13 shows that for all the vertical stress levels applied, the analysis could not reach the final displacement of $20 \mathrm{~mm}$; by all means, the values found for peak horizontal forces vary linearly with vertical load. Fig. 14 shows that the peak horizontal forces correspond to the same displacement.

Fig. 15 shows the distribution of shear stress can be observed for the DP model and P\#2 materials with a vertical stress value of $p=1 \mathrm{MPa}$. Fig. 16 shows the mapping of plastic strain for the DP model and P\#2 materials with a vertical stress value of $p=1 \mathrm{MPa}$. Fig. 17 shows the distribution of shear stress for the CDP model and $\mathrm{P} \# 2$ materials with a vertical stress value of $p=1 \mathrm{MPa}$. In Fig. 18, the mapping of plastic strain is shown for the CDP model and $\mathrm{P} \# 2$ materials with a vertical stress value of $p=1 \mathrm{MPa}$.

Fig. 15 shows that shear stress occurs in a central area, approximately at $45^{\circ}$, while Fig. 17 shows that shear stress is concentrated over a larger area. Fig. 16 shows that plastic strain is mostly concentrated on mortar joints, whereas Fig. 18 shows that plastic strain is spread on mortar joints and bricks. Figs. 19-21 compare the responses obtained for the two constitutive models used for $\mathrm{P} \# 2$ materials.

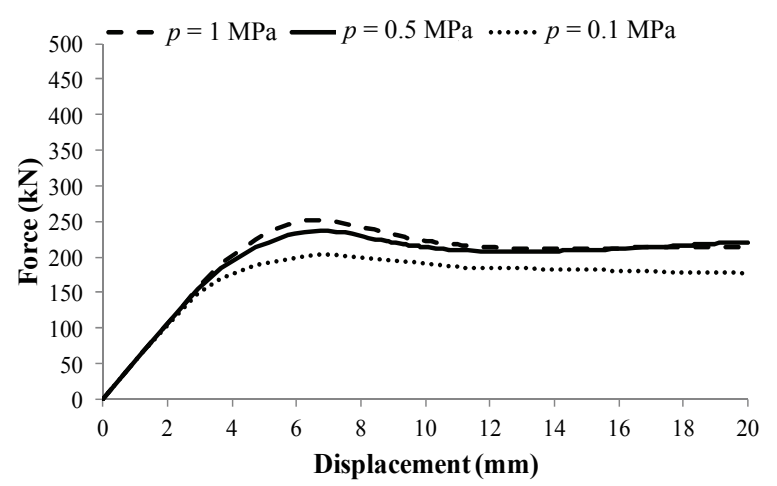

Fig. 14 Force versus displacement curves, CDP model with P\#2 materials $(p=1 \mathrm{MPa}, p=0.5 \mathrm{MPa}$ and $p=0.1 \mathrm{MPa})$. 


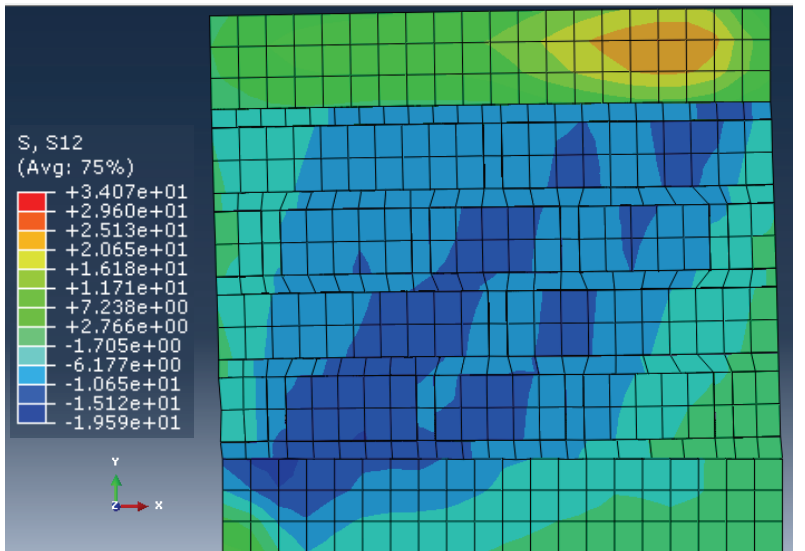

Fig. 15 Status of shear stress, DP model with P\#2 materials, $p=1 \mathrm{MPa}(\mathrm{MPa} \times \mathrm{E}-\mathbf{0 1})$.

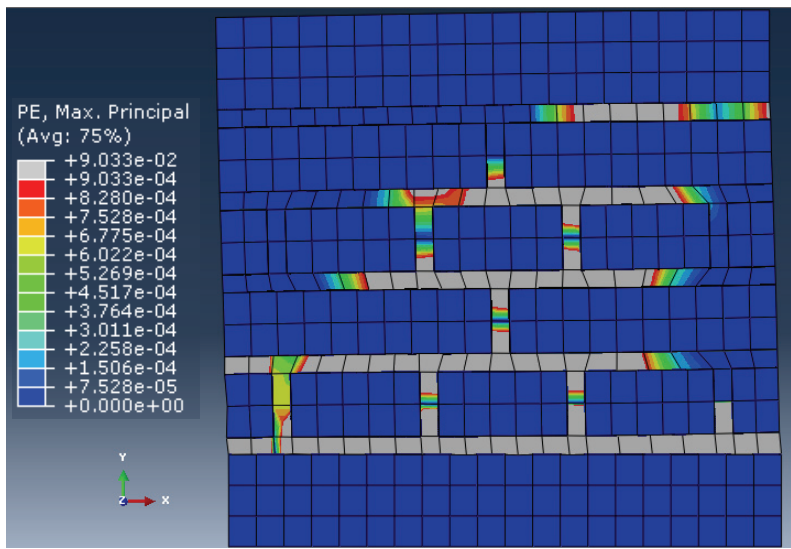

Fig. 16 Mapping of plastic strain, DP model with P\#2 materials, $p=1 \mathrm{MPa}(\mathrm{MPa} \times \mathbf{E}-\mathbf{0 1})$.

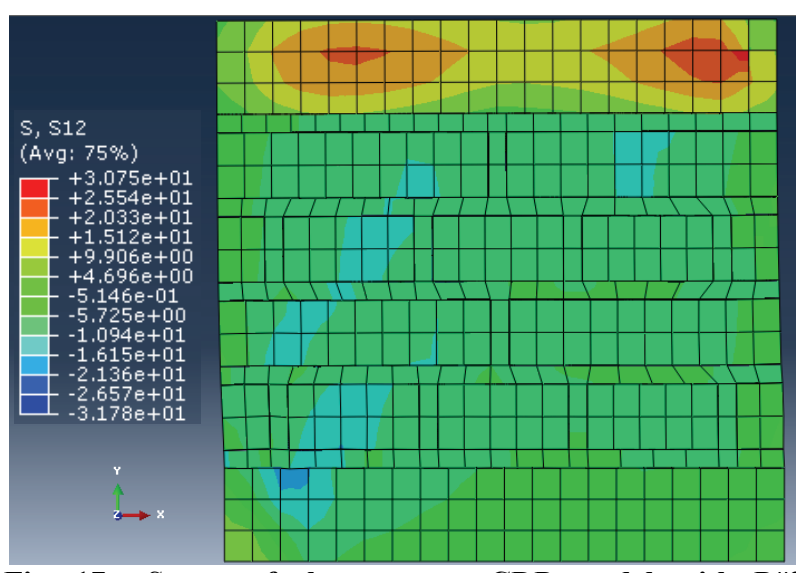

Fig. 17 Status of shear stress, CDP model with $\mathrm{P} \# 2$ materials, $p=1$ MPa $($ MPa $\times$ E-01).

Figs. 10-12 show that for all levels of vertical stress applied, the CDP model leads to a peak horizontal force greater than the DP model. The displacement corresponding to the peak horizontal load is not coincident in any of the cases.

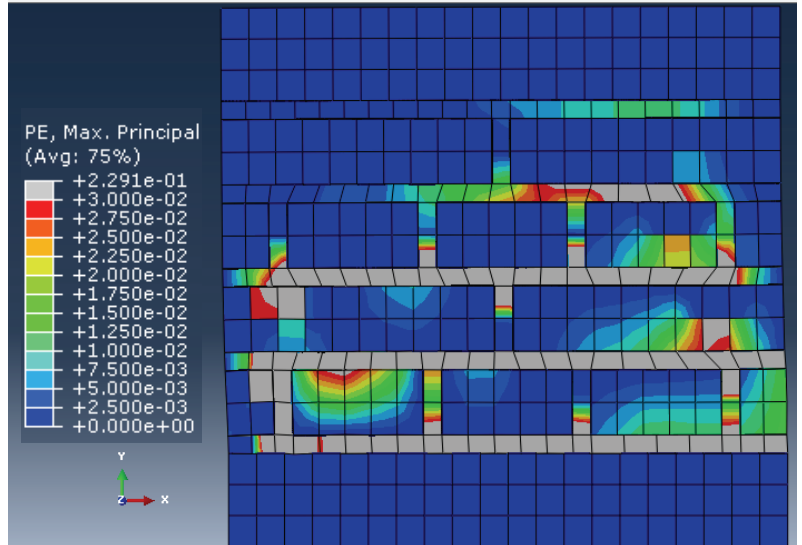

Fig. 18 Mapping of plastic strain, CDP model with P\#2 materials, $p=1 \mathrm{MPa}(\mathrm{MPa} \times \mathbf{E}-\mathbf{0 1})$.

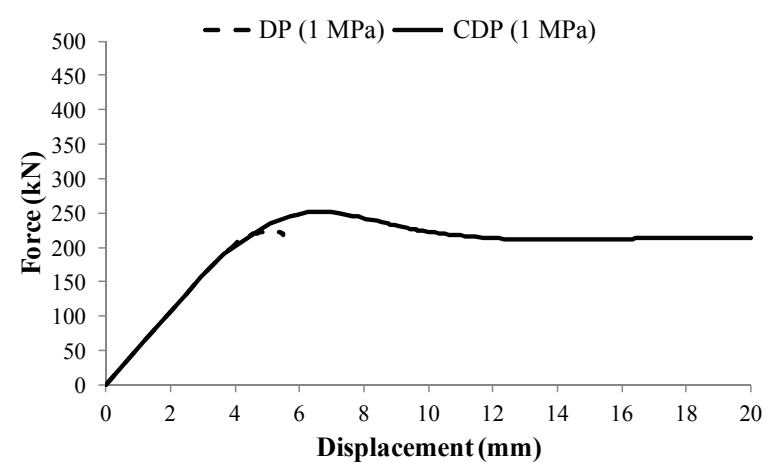

Fig. 19 Force versus displacement curves, comparison between the two models of materials used, $P \# 2$ materials $(p=1 \mathrm{MPa})$.

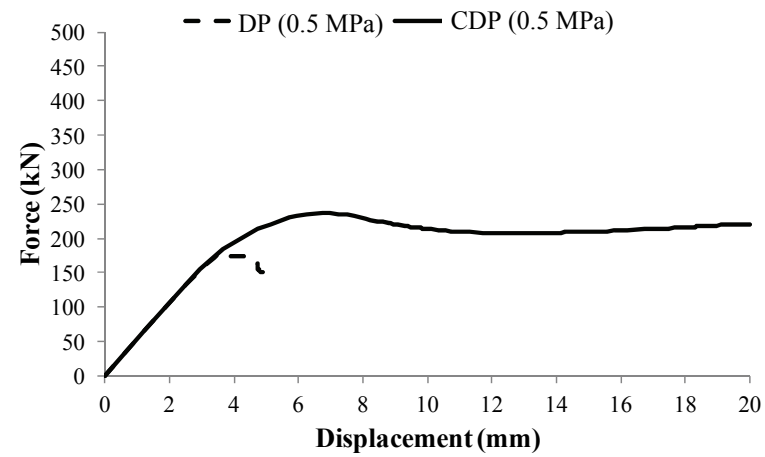

Fig. 20 Force versus displacement curves, comparison between the two models of materials used, P\#2 materials $(p=0.5 \mathrm{MPa})$.

Figs. 22-24 show curves, horizontal load versus and horizontal displacement for the DP model, wall thickness of $450 \mathrm{~mm}$ and a vertical stress load of $0.1 \mathrm{MPa}, \quad 0.5 \mathrm{MPa}$ and $1 \mathrm{MPa}$, respectively. Figs. 22-24 also show wall response for the two kinds of brick and mortar used in the test. 


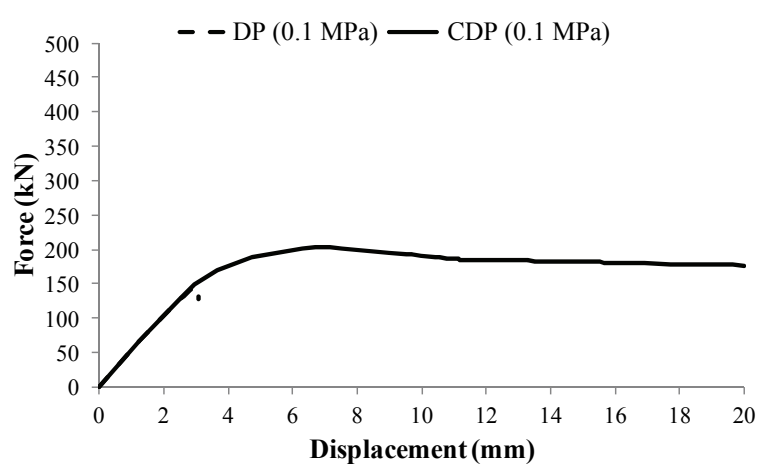

Fig. 21 Force versus displacement curves, comparison between the two models of materials used, P\#2 materials $(p=0.1$ MPa).

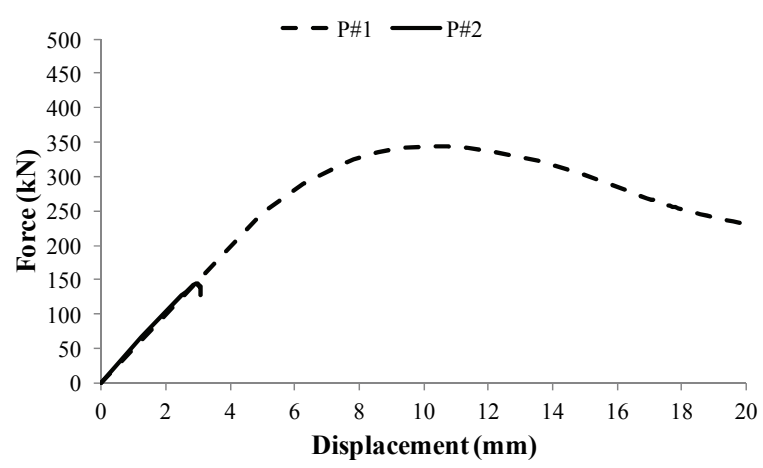

Fig. 22 Force versus displacement curves for the different characteristics of materials (wall thickness: $450 \mathrm{~mm}$; DP model; $p=0.1 \mathrm{MPa})$.

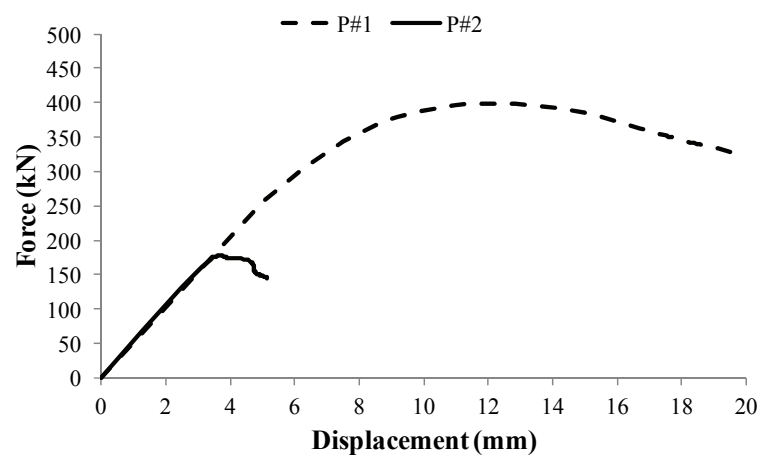

Fig. 23 Force versus displacement curves for the different characteristics of materials (wall thickness: $450 \mathrm{~mm}$; DP model; $p=0.5 \mathrm{MPa})$.

Figs. 25-27 show, for the CDP constitutive model, the comparative curves that relate horizontal load with horizontal displacement for a wall $450 \mathrm{~mm}$ thick and for a vertical stress of $0.1 \mathrm{MPa}, 0.5 \mathrm{MPa}$ and $1 \mathrm{MPa}$, respectively.

Figs. 22-24 suggest that $\mathrm{P} \# 1$ material leads to higher peak horizontal load values compared to $\mathrm{P} \# 2$ material

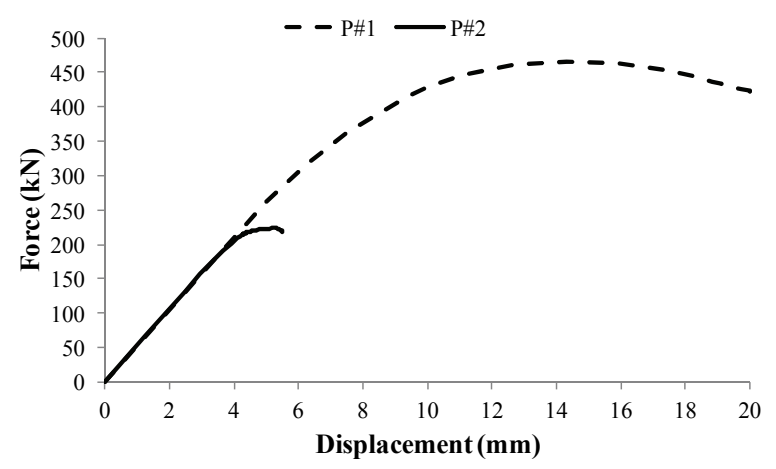

Fig. 24 Force versus displacement curves for the different characteristics of materials (wall thickness: $450 \mathrm{~mm}$; DP Model; $\boldsymbol{p}=1 \mathrm{MPa}$ ).

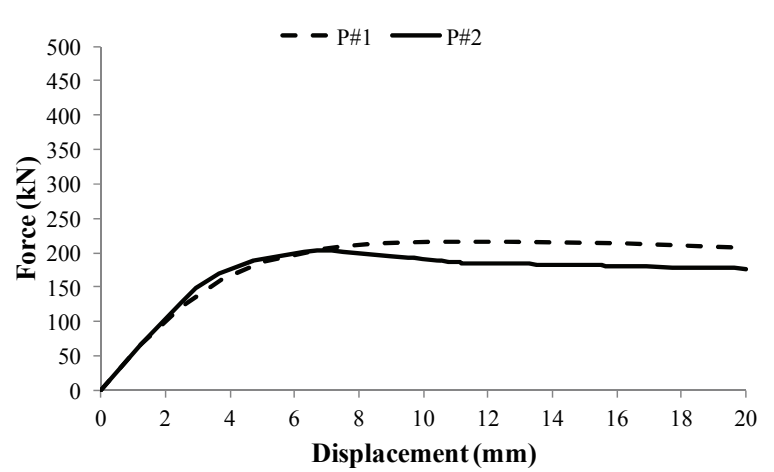

Fig. 25 Force versus displacement curves for the different characteristics of materials (wall thickness: $450 \mathrm{~mm}$; CDP model; $p=0.1 \mathrm{MPa})$.

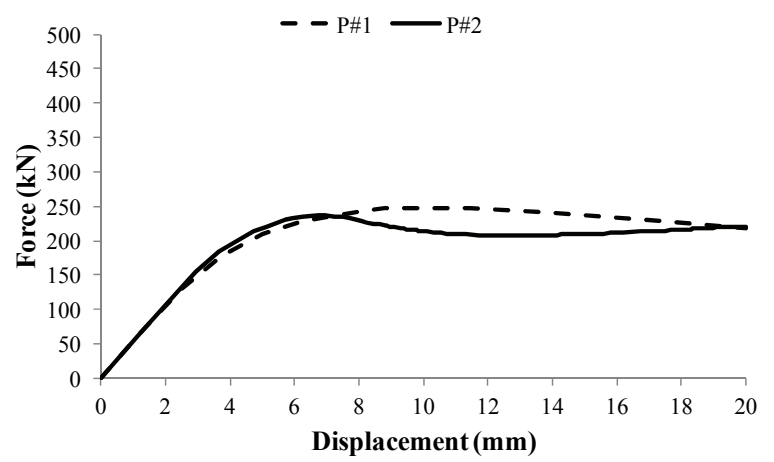

Fig. 26 Force versus displacement curves for the different characteristics of materials (wall thickness: $450 \mathrm{~mm}$; CDP $\operatorname{model} ; p=0.5 \mathrm{MPa})$.

for all levels of vertical stress assigned. Additionally, Figs. 25-27 suggest that both materials (P\#1 and $\mathrm{P} \# 2$ ) lead to similar values of peak horizontal load, with the exception of a vertical stress level of $p=1 \mathrm{MPa}$. Figs. 25 and 26 show that the curves of both materials present similar forms, but in Fig. 27, differences in curve forms are observed depending on the material used. 


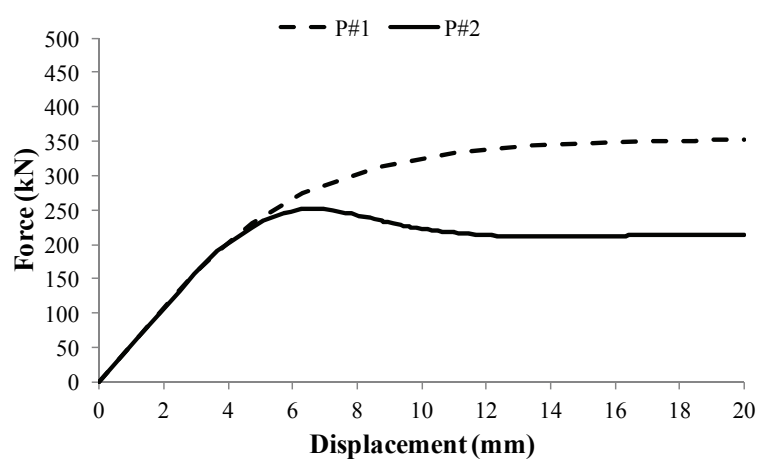

Fig. 27 Force versus displacement curves for the different characteristics of materials (wall thickness: $450 \mathrm{~mm}$; CDP model; $p=1 \mathrm{MPa})$.

When the results obtained are compared, and taking into account that the features of materials ( $\mathrm{P} \# 1$ and $\mathrm{P} \# 2$ ) used in the numerical modeling show differences, it can be concluded that the DP model is greatly dependent on the absolute values of those features. The results found for CDP do not indicate the same, with the exception of a high vertical stress load. The principle expresses that the change in characteristics of the masonry wall constituent materials leads to different responses is not met for the two plasticity models studied in the present work.

\section{Conclusions}

The CDP model and P\#1 materials show significantly different responses as vertical stress values increase. In addition, there are fewer differences for the wall with P\#2 materials. The DP model, for both materials ( $\mathrm{P} \# 1$ and $\mathrm{P} \# 2$ ), provides responses in capacities which increase as vertical stress increases.

Even though plasticity models are different, similarities are found in the forms of response curves, with the exception of the results obtained for $\mathrm{P} \# 2$ materials. The maximum capacity values found in the DP model correspond to P\#1 material, while those for the CDP model correspond to $\mathrm{P} \# 2$ materials.

The DP model and P\#1 materials show a distribution of diagonal shear stress about $45^{\circ}$ with respect to the horizontal, while the CDP model for the same material indicates a more dispersed distribution of shear stress. Therefore, the $45^{\circ}$ diagonal of the CDP model is not so evident. There may be more than one diagonal shear band in the failure mode.

The DP model and P\#2 materials show a plastic strain distribution concentrated in the mortar joints, while that in the CDP model for the same material, plastic strain also reaches the bricks. The result obtained highlights the importance of defining more precisely the type of contact between mortar and brick.

The two plasticity models used in order to predict wall responses show differences manifested at yield onset and in the peak values of load capacity. The structural response of URM walls using numerical modeling is strongly dependent upon these two factors: (1) the type of used plasticity model; (2) the mechanical characteristics of masonry wall materials (bricks, mortar and interface). The choice of numerical model to be used will be experimentally verified in subsequent stages of research.

\section{Acknowledgments}

The authors wish to express their special thanks to the Doctoral Fellowship Program for professors of Universidad Tecnológica Nacional (Argentina), Ministry of Science and Technology of Argentina, and to the CeReDeTeC (Regional Center of Technological Development for Construction, Seismology and Earthquake Engineering) for their support of the present study.

\section{References}

[1] Page, A. W. 1980. "A Biaxial Failure Criterion for Brick Masonry in the Tension-Tension Range." Int. Journal Masonry Constr. 1 (1): 26-9.

[2] Page, A. W. 1982. "An Experimental Investigation of the Biaxial Strength of Brick Masonry." In Proc. Sixth Int. Brick Masonry Conf., 3-15.

[3] Samarasinghe, W., Page, A. W., and Hendry, A. W. 1981. "Behaviour of Masonry Shear Walls." Struct Eng. 59B (3): 42-8.

[4] Mann, W., and Müller, H. 1982. "Failure of Shear-Stressed Masonry-An Enlarged Theory, Test and Applications to Shear Walls." In Proc. of the British Ceramic Society, 223-35. 
[5] Lourenco, P. B., Rots, J. G., and Blaauwendraad, J. 1998. "Two Approaches for the Analysis of Masonry Structures: Micro- and Macro-Modeling." Heron 40 (4): 313-40.

[6] Anthoine, A., Magonette, G., and Magenes, G. 1995. "Shear-Compression Testing and Analysis of Brick Masonry Wall." In Proceedings of 10th European Conference on Earthquake Engineering 3, 1657-62.

[7] Calvi, G. M., Kingsley, G. R., and Magenes, G. 1996. "Testing of Masonry Structures for Seismic Assessment, Earthquake Spectra." Journal of Earthquake Engineering Research Institute 12 (1): 145-62.

[8] Vermeltfoort, A. T., and Raijmakers, T. M. J. 1993. Deformation Controlled Tests in Masonry Shear Walls, Part 2. Report TUE/BKO/93.08, Eindhoven University of Technology, Eindhoven, the Netherlands.

[9] Atkinson, R. H., Amadei, B. P., Saeb, S., and Sture, S. 1989. "Response of Masonry Bed Joints in Direct Shear." Journal of Structural Engineering 115 (9): 2277-96.

[10] Bosiljkov, V., Page, A. W., Bokan, B. V., and Žarnic, R. 2003. "Performance Based Studies of In-plane Loaded Unreinforced Masonry Walls." Masonry International 16 (2): 39-50.

[11] Magenes, G. 1992. "Seismic Behavior of Brick Masonry: Strength and Failure Mechanisms." Ph.D. thesis, Department of Structural Mechanics, University of Pavia.

[12] López, J., Oller, S., and Oñate, E. 1998. Calculating the
Behavior of Masonry by Finite Element. Barcelona: CIMNE (Centre Internacional de Mètodes Numèrics a l'Enginyeria) Monograph M46.

[13] Lourenço, P. B., Milani, G., Tralli, A., and Zucchini, A. 2007. "Analysis of Masonry Structures: Review of and Recent Trends of Homogenization Techniques." Canadian Journal of Civil Engineering 34: 1443-57.

[14] Roca, P., Cervera, M., Giuseppe, G., and Pela, L. 2010. "Structural Analysis of Masonry Historical Constructions." Archives of Computational Methods in Engineering 17: 299-325.

[15] Aref, A. J., and Dolatshashi, K. M. 2013. "A Three-Dimensional Cyclic Meso-scale Numerical Procedure for Simulation of Unreinforced Masonry Structures." Computers and Structures 120: 9-23.

[16] Abaqus Inc. 2003. Abaqus Analysis User Manual. California: Abaqus Inc.

[17] Mase, G. E. 1977. Theory and Problems of Continuum Mechanics. Ciudad de México: McGraw-Hill Education, 247.

[18] Martín, P. E., Sanchez, A. A., González del Solar, G. A., and Maldonado, N. G. 2012. "Non-linear Analysis of Walls of Considerable Width through the Application of Surface Interaction in Abaqus." In Proceedings of the X Congreso Argentino de Mecánica Computacional, 1125-37. 